\title{
Cortical Bone Thickness in Dentate and Edentulous Human Cadavers
}

\author{
Amar Katranji, * Kelly Misch, * and Hom-Lay Wang*
}

Background: A critical component of treatment planning in dental implant therapy is the amount of available bone. Thick cortical plates have been the primary way to achieve primary implant stability. However, information about cortical bone thickness in various regions of the maxilla and mandible is largely missing. Hence, it was the purpose of this cadaver study to determine an average cortical bone thickness in different tooth locations.

Methods: To determine the average thickness of buccal and lingual plates, 28 cadaver heads (68\% male and 32\% female) with an average age of 73.1 years were measured at various locations correlating to molar (M), premolar (PM), and anterior (A) regions. Edentulous and dentate regions also were recorded.

Results: Average buccal cortical thicknesses were $1.69 \mathrm{~mm}$ (M), $1.43 \mathrm{~mm}(\mathrm{PM})$, and $1.04 \mathrm{~mm}(\mathrm{~A})$ in the edentulous maxilla; $2.06 \mathrm{~mm}(\mathrm{M}), 1.78 \mathrm{~mm}(\mathrm{PM})$, and $1.36 \mathrm{~mm}(\mathrm{~A})$ in the edentulous mandible; $2.23 \mathrm{~mm}(\mathrm{M}), 1.62 \mathrm{~mm}(\mathrm{PM})$, and $1.59 \mathrm{~mm}(\mathrm{~A})$ in the dentate maxilla; and $1.98 \mathrm{~mm}(\mathrm{M}), 1.20$ $\mathrm{mm}(\mathrm{PM})$, and $0.99 \mathrm{~mm}(\mathrm{~A})$ in the dentate mandible. Average lingual cortical thicknesses were $2.06 \mathrm{~mm}(M), 1.60 \mathrm{~mm}(P M)$, and $1.36 \mathrm{~mm}(\mathrm{~A})$ in the edentulous maxilla; $2.39 \mathrm{~mm}(\mathrm{M})$, $1.88 \mathrm{~mm}(\mathrm{PM})$, and $1.66 \mathrm{~mm}(\mathrm{~A})$ in the edentulous mandible; $2.35 \mathrm{~mm}(\mathrm{M}), 2.0 \mathrm{~mm}(\mathrm{PM})$, and $1.95 \mathrm{~mm}(\mathrm{~A})$ in the dentate maxilla; and $2.51 \mathrm{~mm}(\mathrm{M}), 1.92 \mathrm{~mm}(\mathrm{PM})$, and $1.24 \mathrm{~mm}(\mathrm{~A})$ in the dentate mandible.

Conclusions: The average cortical thickness of the buccal plates ranged from 1.0 to $2.1 \mathrm{~mm}$ in the edentulous maxilla and mandible, with the thinnest area in the anterior maxilla and the thickest area in the posterior mandible. The buccal plate of the dentate maxilla and mandible ranged from 1.6 to $2.2 \mathrm{~mm}$ in thickness, with the thinnest area in the lower anterior region and the thickest area in the upper posterior region. J Periodontol 2007;78:874-878.

\section{KEY WORDS}

Bone; cortical; dentate; edentulous; implants; thickness.

\footnotetext{
* Department of Periodontics and Oral Medicine, School of Dentistry, University of Michigan, Ann Arbor, MI.
}

$\mathrm{T}$ he determination of bone morphology and quality is a critical step in predicting treatment outcome in implant therapy. Implant stability is necessary for osseointegration and is aided largely by cortical bone. Many classifications are available to assist clinicians in determining the bony quality and quantity. ${ }^{1-3}$ Lekholm and Zarb ${ }^{1}$ classified bone quality according to cortical and cancellous bone content; they reported that patients with an adequate amount of cortical thickness surrounding a cancellous region (type II and III) are best suited for implant therapy. However, in their classification, the operator is left to subjectively determine the composition and classification of the bone. Later, Misch $^{3}$ proposed a classification using bone density. Five types of bone densities were classified and could be assigned objectively, based on the Hounsfield unit (HU) to which it corresponded. D1 bone density was defined as dense cortical bone with $>1,250 \mathrm{HU}$. D2 bone density corresponded to an outer dense bone surrounding a coarse trabecular bone with a range of 850 to $1,250 \mathrm{HU}$. D3 bone density had thin porous cortical bone encapsulating fine trabecular bone and ranged from 350 to $850 \mathrm{HU}$. D4 bone was fine trabecular bone with a range of 150 to $350 \mathrm{HU}$, and D5 bone was immature non-mineralized bone with $<150 \mathrm{HU}$. Although similar to the Lekholm and Zarb classification, the Misch classification used diagnostic imaging for bone assessment allowing for easier preoperative planning.

doi: 10.1902/jop.2007.060342 
The morphology of bone also has been characterized and classified to facilitate predictable implant therapy. Seibert ${ }^{4}$ classified the ridge based on soft tissue deficiencies. Implications on therapeutic measures were determined by the orientation of the defect. Later, Wang and Al-Shammari ${ }^{2}$ introduced a therapeutically oriented classification based on hard and soft tissue defects of the ridge. Both of these classifications focus on morphological properties of the ridge, and they should be used with the bone quality classification during implant therapy.

The impact of bone quality on implant therapy also has been studied. Recent findings suggested that the cortical thickness of bone played a greater role in initial implant stability than the implant length. ${ }^{5} \mathrm{~A}$ previous animal report ${ }^{6}$ found that implants placed in cortical bone required greater removal torque than those placed in cancellous bone. Furthermore, this torque remained constant over time for cortically placed implants, whereas removal torque increased over time for implants placed in cancellous bone. These findings suggested that adequate cortical engagement is necessary when placing dental implants. The influence of bicortical anchorage on implant stability also was studied recently. ${ }^{7}$ Investigators looked at cortical fixation at the crestal and apical regions and found no benefits for implant success. However, the relative thickness of the cortical plate has yet to be determined based on dentition in human cadaver studies, and none of the current bone classifications provide quantitative measures on cortical bone thickness. The present study attempted to approximate the thickness of the lingual and buccal cortical plates in various regions of the maxilla and mandible and tried to quantify deficient implant sites based on the cortical thickness of the ridge.

\section{MATERIALS AND METHODS}

Nineteen male and nine female human cadaver heads (mean age, 73.1 years) were used in this study. The cadaver heads were donated to the University of Michigan Anatomy Department for educational purposes; they were used for the present study after academic use. Full-thickness reflection of the mandible and maxilla to expose the underlying bone for accurate measurements in the molar, premolar, and anterior regions were identified and marked for analysis. These areas were estimated in edentulous areas by dividing the quadrants into thirds and labeling the distal-most area as the molar region, the middle third as the premolar region, and the anterior-most area as the anterior region. Attempts were made to gather information from the right and left side of each cadaver head when possible. Teeth were extracted carefully by elevation and forceps delivery; measurements were taken using a digital Boley gauge caliper ${ }^{\dagger}$ at the alveolar crest and $3 \mathrm{~mm}$ apical to the crest. The crest was ground down $3 \mathrm{~mm}$ in edentulous areas to reveal the cortical and cancellous regions. This depth was used because crestal resorption is a common phenomenon postextraction and where the crestal third of an implant is located. ${ }^{8}$ One examiner took a single measurement at each designated site, whereas three individuals performed extractions and flap reflections. The descriptive statistics were used in the study with no intent of finding any statistical differences. The mean \pm SD was calculated for all measured variables.

\section{RESULTS}

Bilateral measurements were made on 22 subjects. Measurements from each subject were not included in each category; certain areas were not measurable because of varying levels of preservation. All subjects were pooled into the same group for analysis, regardless of bilateral measurements.

\section{Width of Alveolar Crest (Table 1)}

The width of the edentulous mandible at the alveolar crest is summarized in Table 1 . The width at $3 \mathrm{~mm}$ below the alveolar crest increased to $7.31 \pm 2.16 \mathrm{~mm}$, $6.77 \pm 1.63 \mathrm{~mm}$, and $5.29 \pm 2.37 \mathrm{~mm}$ in the molar, premolar, anterior regions, respectively. The width of the edentulous maxilla at the alveolar crest was $7.88 \pm$ $2.26 \mathrm{~mm}, 5.10 \pm 2.20 \mathrm{~mm}$, and $3.76 \pm 2.49 \mathrm{~mm}$ in the molar, premolar, and anterior regions, respectively. This also increased at $3 \mathrm{~mm}$ below the crest to $8.29 \pm$ $2.57 \mathrm{~mm}, 5.15 \pm 1.96 \mathrm{~mm}$, and $4.02 \pm 0.94 \mathrm{~mm}$ in the molar, premolar, and anterior regions, respectively.

The alveolar crest of the dentate maxilla was $10.18 \pm$ $1.30 \mathrm{~mm}$ in the molar region, $6.74 \pm 2.08 \mathrm{~mm}$ in the premolar region, and $7.57 \pm 1.29 \mathrm{~mm}$ in the anterior region. All measurements increased at $3 \mathrm{~mm}$ below the alveolar crest to $11.39 \pm 2.49 \mathrm{~mm}$ in the molar region, $7.86 \pm 2.18 \mathrm{~mm}$ in the premolar region, and $8.05 \pm 1.44 \mathrm{~mm}$ in the anterior region. The alveolar crest of the dentate mandible was $9.52 \pm 1.0 \mathrm{~mm}$ in the molar region, $6.59 \pm 1.26 \mathrm{~mm}$ in the premolar region, and $6.40 \pm 1.22 \mathrm{~mm}$ in the anterior region. These measurements increased at $3 \mathrm{~mm}$ below the alveolar crest in the premolar and anterior regions, but decreased in the molar area to $9.29 \pm 1.0 \mathrm{~mm}$ in the molar region, $8.3 \pm 1.10 \mathrm{~mm}$ in the premolar region, and $7.14 \pm 0.59 \mathrm{~mm}$ in the anterior region.

\section{Buccal Cortical Plate Thickness (Table 2)}

In the edentulous maxilla, the average thickness of the buccal plate was $1.69 \pm 0.51 \mathrm{~mm}$ in the molar region, $1.43 \pm 0.61 \mathrm{~mm}$ in the premolar region, and $1.04 \pm 0.29 \mathrm{~mm}$ in the anterior region. The edentulous

$\dagger$ Salvin Dental, Charlotte, NC. 
Table I.

\section{Summary of Initial Measurements}

\begin{tabular}{|c|c|c|c|}
\hline & Molar & Premolar & Anterior \\
\hline \multicolumn{4}{|l|}{ Maxillary edentulous } \\
\hline Width at alveolar crest (mm) & $\begin{array}{c}7.88 \pm 2.26 \\
(n=19)\end{array}$ & $\begin{array}{c}5.10 \pm 2.20 \\
(n=18)\end{array}$ & $\begin{array}{c}3.76 \pm 2.46 \\
(n=13)\end{array}$ \\
\hline Width $3 \mathrm{~mm}$ below alveolar crest $(\mathrm{mm})$ & $\begin{array}{c}8.29 \pm 2.57 \\
(n=19)\end{array}$ & $\begin{array}{c}5.15 \pm 1.96 \\
(n=18)\end{array}$ & $\begin{array}{c}4.02 \pm 0.96 \\
(n=13)\end{array}$ \\
\hline \multicolumn{4}{|l|}{ Mandibular edentulous } \\
\hline Width at alveolar crest (mm) & $\begin{array}{c}6.02 \pm 1.67 \\
(n=19)\end{array}$ & $\begin{array}{c}4.82 \pm 2.16 \\
(n=14)\end{array}$ & $\begin{array}{c}3.64 \pm 1.83 \\
(n=12)\end{array}$ \\
\hline Width $3 \mathrm{~mm}$ below alveolar crest ( $\mathrm{mm})$ & $\begin{array}{c}7.31 \pm 2.16 \\
(n=19)\end{array}$ & $\begin{array}{c}6.77 \pm 1.63 \\
(n=14)\end{array}$ & $\begin{array}{c}5.29 \pm 2.37 \\
(n=12)\end{array}$ \\
\hline \multicolumn{4}{|l|}{ Maxillary dentition } \\
\hline Width at alveolar crest (mm) & $\begin{array}{c}10.18 \pm 1.30 \\
(n=21)\end{array}$ & $\begin{array}{c}6.74 \pm 2.08 \\
(n=21)\end{array}$ & $\begin{array}{c}7.57 \pm 1.29 \\
(n=15)\end{array}$ \\
\hline Width $3 \mathrm{~mm}$ below alveolar crest ( $\mathrm{mm})$ & $\begin{array}{c}11.39 \pm 2.49 \\
(n=21)\end{array}$ & $\begin{array}{c}7.86 \pm 2.18 \\
(n=21)\end{array}$ & $\begin{array}{c}8.05 \pm 1.44 \\
(n=15)\end{array}$ \\
\hline \multicolumn{4}{|l|}{ Mandibular dentition } \\
\hline Width at alveolar crest (mm) & $\begin{array}{l}9.52 \pm 1.0 \\
(n=18)\end{array}$ & $\begin{array}{c}6.59 \pm 1.26 \\
(n=16)\end{array}$ & $\begin{array}{c}6.40 \pm 1.22 \\
(n=13)\end{array}$ \\
\hline Width $3 \mathrm{~mm}$ below alveolar crest ( $\mathrm{mm})$ & $\begin{array}{c}9.29 \pm 1.0 \\
(n=18)\end{array}$ & $\begin{array}{c}8.30 \pm 1.10 \\
(n=16)\end{array}$ & $\begin{array}{c}7.14 \pm 0.59 \\
(n=13)\end{array}$ \\
\hline
\end{tabular}

Data are mean \pm SD.

Table 2.

\section{Summary of Buccal and Lingual Cortical Plate Thickness}

\begin{tabular}{lccc}
\hline & Molar & Premolar & Anterior \\
\hline Width of buccal cortical plate $(\mathrm{mm})$ & & \\
Edentulous maxilla & $1.69 \pm 0.51$ & $1.43 \pm 0.61$ & $1.04 \pm 0.29$ \\
& $(n=19)$ & $(n=18)$ & $(n=13)$ \\
Dentate maxilla & $2.23 \pm 0.84$ & $1.62 \pm 0.48$ & $1.59 \pm 0.7 \mid$ \\
& $(n=21)$ & $(n=21)$ & $(n=15)$ \\
Edentulous mandible & $2.06 \pm 0.69$ & $1.78 \pm 0.74$ & $1.36 \pm 0.81$ \\
& $(n=19)$ & $(n=14)$ & $(n=12)$ \\
Dentate mandible & $1.98 \pm 0.81$ & $1.20 \pm 0.41$ & $0.99 \pm 0.53$ \\
& $(n=18)$ & $(n=16)$ & $(n=13)$ \\
Width of lingual cortical plate $(m m)$ & & \\
Edentulous maxilla & $2.06 \pm 0.66$ & $1.60 \pm 0.64$ & $1.36 \pm 0.45$ \\
& $(n=19)$ & $(n=18)$ & $(n=13)$ \\
Dentate maxilla & $2.35 \pm 0.24$ & $2.00 \pm 0.33$ & $1.95 \pm 0.70$ \\
& $(n=21)$ & $(n=21)$ & $(n=15)$ \\
Edentulous mandible & $2.39 \pm 0.62$ & $1.88 \pm 0.50$ & $1.66 \pm 1.04$ \\
& $(n=19)$ & $(n=14)$ & $(n=12)$ \\
Dentate mandible & $2.51 \pm 0.69$ & $1.92 \pm 0.7$ & $1.24 \pm 0.41$ \\
& $(n=18)$ & $(n=16)$ & $(n=13)$ \\
\hline
\end{tabular}

mandible had an average buccal plate thickness of $2.06 \pm 0.69 \mathrm{~mm}$ in the molar region, $1.78 \pm 0.74 \mathrm{~mm}$ in the premolar region, and $1.36 \pm 0.81 \mathrm{~mm}$ in the anterior region.
In the dentate maxilla, the average thickness of the buccal plate was $2.23 \pm 0.84 \mathrm{~mm}$ in the molar region, $1.62 \pm 0.48 \mathrm{~mm}$ in the premolar region, and $1.59 \pm 0.71 \mathrm{~mm}$ in the anterior region. The dentate mandible had an average buccal plate thickness of $1.98 \pm 0.81 \mathrm{~mm}$ in the molar region, $1.20 \pm 0.41 \mathrm{~mm}$ in the premolar region, and $0.99 \pm 0.53 \mathrm{~mm}$ in the anterior region.

\section{Lingual Cortical Plate Thickness (Table 2)}

In the edentulous maxilla, the average thickness of the lingual cortical plate was $2.06 \pm 0.66 \mathrm{~mm}$ in the molar region, $1.60 \pm 0.64 \mathrm{~mm}$ in the premolar region, and $1.36 \pm 0.45 \mathrm{~mm}$ in the anterior region. The edentulous mandible had an average lingual cortical plate thickness of $2.39 \pm 0.62 \mathrm{~mm}$ in the molar region, $1.88 \pm 0.50 \mathrm{~mm}$ in the premolar region, and $1.66 \pm 1.04$ $\mathrm{mm}$ in the anterior region. In the dentate maxilla, the average thickness of the lingual plate was $2.35 \pm 0.24 \mathrm{~mm}$ in the molar region, $2.0 \pm 0.33 \mathrm{~mm}$ in the premolar region, and $1.95 \pm 0.70 \mathrm{~mm}$ in the anterior region. The dentate mandible had an average lingual plate thickness of $2.51 \pm 0.69 \mathrm{~mm}$ in the molar region, $1.92 \pm 0.70 \mathrm{~mm}$ in the premolar region, and $1.24 \pm 0.41 \mathrm{~mm}$ in the anterior region.

\section{Percentage of Cortical Bone in Alveolar Ridge}

The percentage of cortical bone in the edentulous alveolar ridge was determined in each region. This was calculated by adding the buccal and lingual plate thickness and dividing it by the width $3 \mathrm{~mm}$ below the alveolar crest. The estimated thickness of the cancellous bone is shown in Figures 1 and 2.

\section{DISCUSSION}

The present quantitative human cadaver head study clearly demonstrated that different cortical thicknesses exist (e.g., anteriors, premolars, or molars). The anterior and premolar regions of the maxilla had a greater cortical bone thickness than the mandible immediately following tooth extraction. Also, a tendency for greater buccal bone thickness in the molar region was noted in the maxilla, although this was minimal. This is an interesting finding because the maxilla is considered to be of softer bone quality than its mandibular counterpart, but it may offer more cortical bone, especially in the anterior and premolar regions, for primary stability. However, when teeth are 
Molar

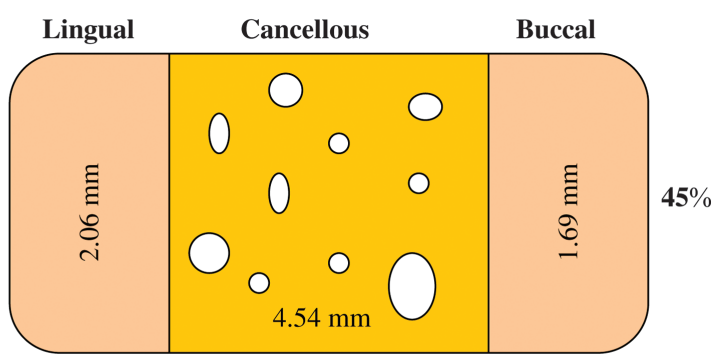

Premolar

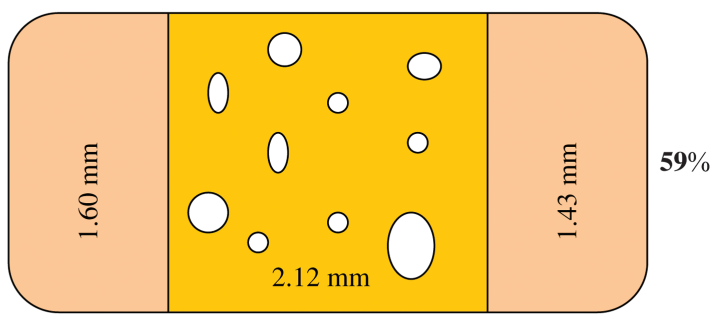

Anterior

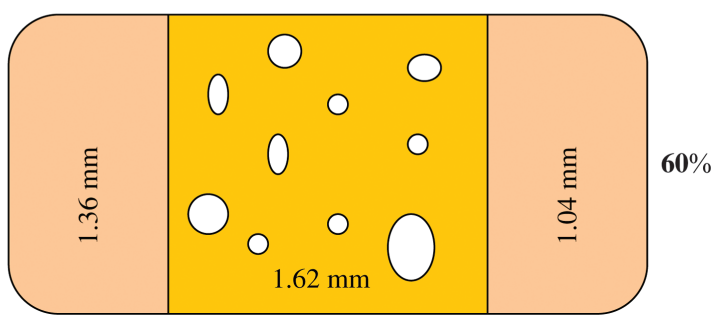

Figure I.

Percentage of bone components in edentulous maxilla.
Molar

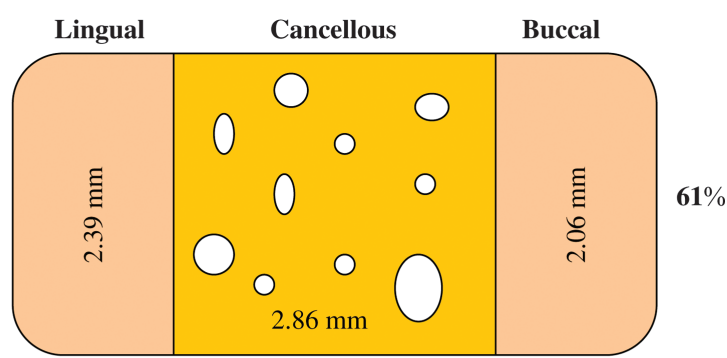

Premolar

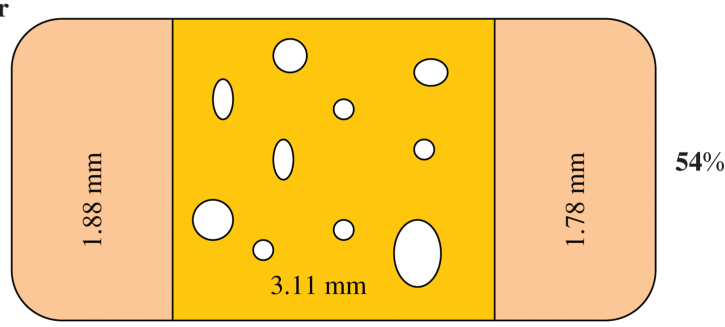

Anterior

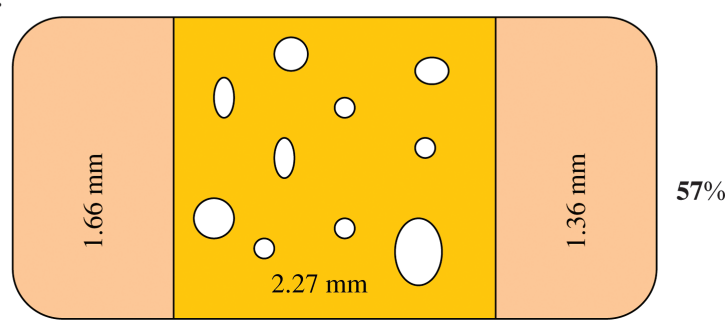

Figure 2.

Percentage of bone components in edentulous mandible.

regions, which compared favorably to the present study.

Another study ${ }^{13}$ found that edentulous mandibles had significantly thinner cortical bone than dentate mandibles. Cortical thickness was greatest in the anterior region and least in the posterior region. Our study showed a trend for thicker cortical bone in the molar region of dentate and edentulous mandibles. The difference in outcome may be due to the location of measurement; our measurements were taken from regions of dentition, whereas Schwartz-Dabney and Dechow ${ }^{13}$ included sites from all regions of the mandible, including the ascending ramus, angle, and below the inferior alveolar nerve.

Edentulous ridges often present with insufficient width for implant placement. One technique developed by Simion et al. ${ }^{14}$ took advantage of the orthopedic concept of greenstick fractures and applied it to atrophic alveolar ridges. Commonly referred to as "ridge splitting," this technique requires a minimum amount of cancellous bone to nourish the fractured bone. In our study, $\sim 60 \%$ of the mandibular molar region was cortical. An alveolar ridge of $3 \mathrm{~mm}$ may not be suitable for this technique because it leaves $<1 \mathrm{~mm}$ of cancellous bone for nutrient supply during healing of the fracture. ranged from 1.3 to $2.0 \mathrm{~mm}$ in the premolar and molar 


\section{CONCLUSIONS}

The data from our study may suggest that it is easier to obtain implant stability in a dentate maxilla or an edentulous mandible because they have thicker total cortical bone. The dentate maxilla had a buccal cortical thickness of 1.59 to $2.23 \mathrm{~mm}$ and a lingual cortical thickness of 1.95 to $2.35 \mathrm{~mm}$, whereas in the edentulous maxilla these ranged from 1.04 to $1.69 \mathrm{~mm}$ and from 1.36 to $2.06 \mathrm{~mm}$, respectively. In the edentulous mandible, the buccal cortical thickness ranged from 1.36 to $2.06 \mathrm{~mm}$ and the lingual cortical thickness ranged from 1.66 to $2.39 \mathrm{~mm}$; in the dentate mandible, these measurements were 0.99 to $1.98 \mathrm{~mm}$ and 1.24 to $2.51 \mathrm{~mm}$, respectively.

\section{ACKNOWLEDGMENT}

This work was supported, in part, by the University of Michigan Periodontal Graduate Student Research Fund.

\section{REFERENCES}

1. Lekholm $U$, Zarb GA. Patient selection and preparation. In: Brånemark P-I, Zarb GA, Albrektsson T, eds. Tissue Integrated Prostheses. Osseointegration in Clinical Dentistry, 3rd ed. Chicago: Quintessence Publishing Co.; 1985:199-209.

2. Wang HL, Al-Shammari K. HVC ridge deficiency classification: A therapeutically oriented classification. Int $J$ Periodontics Restorative Dent 2002;22:335-343.

3. Misch CE. Contemporary implant dentistry. In: Misch CE, ed. Density of Bone: Effect on Treatment Planning, Surgical Approach, and Healing. St. Louis: Mosby Year Book; 1993:469-485.

4. Seibert JS. Reconstruction of deformed, partially edentulous ridges, using full thickness onlay grafts. Part II. Prosthetic/periodontal interrelationships. Compend Contin Educ Dent 1983;4:549-562.

5. Miyamoto I, Tsuboi Y, Wada E, Suwa H, lizuka T. Influence of cortical bone thickness and implant length on implant stability at the time of surgery - Clinical, prospective, biomechanical, and imaging study. Bone 2005;37:776-780.

6. Sennerby L, Thomsen P, Ericson LE. A morphometric and biomechanic comparison of titanium implants inserted in rabbit cortical and cancellous bone. Int $J$ Oral Maxillofac Implants 1992;7:62-71.

7. Ivanoff CJ, Grondahl K, Bergstrom C, Lekholm U, Branemark PI. Influence of bicortical or monocortical anchorage on maxillary implant stability: A 15-year retrospective study of Brånemark system implants. Int J Oral Maxillofac Implants 2000;15:103-110.

8. Araujo MG, Lindhe J. Dimensional ridge alterations following tooth extraction. An experimental study in the dog. J Clin Periodontol 2005;32:212-218.

9. Lioubavina-Hack N, Lang NP, Karring T. Significance of primary stability for osseointegration of dental implants. Clin Oral Implants Res 2006;17:244-250.

10. Heibel H, Alt KW, Wachter R, Bahr W. Cortical thickness of the mandible with special reference to miniplate osteosynthesis. Morphometric analysis of autopsy material (in German). Mund Kiefer Gesichtschir 2001;5:180-185.

11. Carter TB, Frost DE, Tucker M, Zuniga JR. Cortical thickness in human mandibles: Clinical relevance to the sagittal split ramus osteotomy. Int J Adult Orthodon Orthognath Surg 1991;6:257-260.

12. Deguchi T, Nasu M, Murakami K, Yabuuchi T, Kamioka H, Takano-Yamamoto T. Quantitative evaluation of cortical bone thickness with computed tomographic scanning for orthodontic implants. Am J Orthod Dentofacial Orthop 2006;129:721.e7-12.

13. Schwartz-Dabney CL, Dechow PC. Edentulation alters material properties of cortical bone in the human mandible. J Dent Res 2002;81:613-617.

14. Simion M, Baldoni M, Zaffe D. Jawbone enlargement using immediate implant placement associated with a split-crest technique and guided tissue regeneration. Int J Periodontics Restorative Dent 1992;12:462-473.

Correspondence: Dr. Hom-Lay Wang, Department of Periodontics and Oral Medicine, University of Michigan, School of Dentistry, 1011 N. University Ave., Ann Arbor, MI 48109-1078. Fax: 734/936-0374; e-mail: homlay@ umich.edu.

Accepted for publication November 6, 2006. 